Molecular biology

\title{
Functional characterization of new mutations in Wilson disease gene (ATP7B) using the yeast model
}

\author{
Ozlenen Simsek Papur ${ }^{\mathrm{a}}$, Orhan Terzioglu ${ }^{\mathrm{a}}$, Ahmet Koc ${ }^{\mathrm{b}, *}$ \\ a Department of Medical Biology and Genetics, Faculty of Medicine, Dokuz Eylul University, Izmir, Turkey \\ ${ }^{\mathrm{b}}$ Department of Molecular Biology and Genetics, Izmir Institute of Technology, 35430 Urla, Izmir, Turkey
}

\section{A R T I C L E I N F O}

\section{Article history:}

Received 16 April 2014

Accepted 25 February 2015

\section{Keywords:}

ATP7B

Wilson disease

Copper

Saccharomyces cerevisiae

$\mathrm{CCC} 2$

\begin{abstract}
A B S T R A C T
The Wilson disease gene, a copper transporting ATPase (Atp7b), is responsible for the sequestration of $\mathrm{Cu}$ into secretory vesicles, and this function is exhibited by the orthologous $\mathrm{Ccc} 2 \mathrm{p}$ in the yeast. In this study, we aimed to characterize clinically relevant new mutations of human ATP7B (p.T788I, p.V1036I and p.R1038G-fsX83) in yeast lacking the CCC2 gene. Expression of human wild type ATP7B gene in ccc2 $\Delta$ mutant yeast restored the growth deficiency and copper transport activity; however, expression of the mutant forms did not restore the copper transport functions and only partially supported the cell growth. Our data support that p.T788I, p.V1036I and p.R1038G-fsX83 mutations cause functional deficiency in ATP7B functions and suggest that these residues are important for normal ATP7B function.
\end{abstract}

(C) 2015 Elsevier GmbH. All rights reserved.

\section{Introduction}

Wilson disease (WD, MIM\#277900) is an autosomal recessive disorder of copper metabolism characterized by decreased biliary excretion of copper first described as hepatolenticular degeneration [1]. The excess copper accumulates in various organs and tissues predominantly in the liver, brain, cornea and kidney. The disease is diagnosed on the basis of typical symptoms and conventional biochemical indicators, which include low serum concentration of ceruloplasmin and elevated excretion of urinary copper [2]. The disease has a worldwide frequency of $1 / 30,000$ to $1 / 100,000$ at birth and a carrier frequency of 1 in 90 [3].

Wilson disease is caused by defects in the ATP7B gene (MIM\#606882) that encodes a copper transporting ATPase, ATP7B, which maps on chromosome 13q14.3-q21 [4,5], contains 21 exons and encodes a protein containing of 1464 amino acids. Atp7b has six copper binding sites in the NH2-terminal domain, eight transmembrane domains forming the trans-membrane copper channel and the ATP-binding domain (including nucleotide binding and phosphorylation sub-domains) which converts the energy of ATP hydrolysis to copper transport [6].

ATP7B plays a role in copper transport from hepatocytes to ceruloplasmin which is the major copper carrier in the blood and it also mediates the transport of excessive copper to biliary duct from hepatocytes. These two functions cannot be accomplished

\footnotetext{
* Corresponding author. Tel.: +90 232 7507309; fax: +90 2327507303.

E-mail address: ahmetkoc@iyte.edu.tr (A. Koc).
}

when ATP7B gene is mutated and consequently excessive copper causes damages in various tissues [7]. The severity of the disease and its clinical manifestations show differences depending on the types and the positions of the mutations in ATP7B [8]. Over 350 different mutations have been identified in the ATP7B gene and listed in the HUGO Wilson disease mutation database (http://www.uofa-medical-genetics.org/wilson/index.php).

The functional conservation between yeast and mammalian copper metabolism genes has simplified the characterization of mammalian orthologous and disease-associated mutations in the yeast Saccharomyces cerevisiae. The yeast copper transporting ATPase, Ccc2p, exhibits high sequence homology and, like the human Atp7b protein, is responsible for the compartmentalization of copper into the lumen of the secretory compartment. Ccc2p also provides copper balance in yeast via exporting it out of the cell. Copper is also transported to Fet3p (ferroxidase, orthologous to ceruloplasmin) by Ccc2p [9].

We previously identified p.T788I(c.2363C $>$ T), p.V1036I (c.3106G >A) and p.R1038G-fsX83 (c.3111delC) mutations in the ATP7B gene of Turkish Wilson disease patients [10]. In this work, we constructed these mutations on a yeast expression vector and characterized their functional properties using a yeast complementation assay.

\section{Materials and methods}

\section{PCR and cloning}

The total RNA was isolated from HepG2 cell line (Qiagen RNeasy Mini kit cat. no.: 74104) and then cDNA was obtained (Invitrogen 
Table 1

Primers used in this study.

\begin{tabular}{|c|c|}
\hline Primer name & Primers \\
\hline BP2F & 5'GGGGACAAGTTTGTACAAAAAAGCAGGCTTCATGCCTGAGCAGGAGAGACAGATCAC 3' \\
\hline BP2R & 5'GGGGACCACTTTGTACAAGAAAGCTGGGTCTCAGATGTACTGCTCCTCATCCCT 3' \\
\hline T788I-F & 5'ACA CTT GGC AAA GAG CAA AAT CTC AGA AGC CCT G 3' \\
\hline T788I-R & 5'CAG GGC TTC TGA GAT TTT GCT CTT TGC CAA GTG T 3' \\
\hline V1036I-F & 5'CCA TTA CCC ATG GCA TCC CCA GGG TCA TG 3' \\
\hline V1036I-R & 5'CAT GAC CCT GGG GAT GCC ATG GGT AAT GG 3' \\
\hline R1038G-fsX83-F & 5'CAT GGC GTC CCA GGG TCA TGC GGG 3' \\
\hline R1038G-fsX83-R & 5'CCC GCA TGA CCC TGG GAC GCC ATG 3' \\
\hline $\mathrm{K} 9 \mathrm{~F}$ & 5'TCCAGGACTGTCCATTCTAAATCTCAT 3' \\
\hline K9R & 5'CCTTCCAGGACTTTCCCATCCA 3' \\
\hline Src-actine (F) & 5'ACG TTC CAG CCT TCT ACG TTT CCA 3' \\
\hline Src-actine (R) & 5'ACG TGA GTA ACA CCA TCA CCG GAA 3' \\
\hline gCCC2-F1 & 5'TGA GAG AAG TGA TAC TTG CTG TAC AT 3' \\
\hline gCCC2-R1 & 5'CTT ATG GCT GTA ATT TCA GAA TCT 3' \\
\hline gCCC-F2 & 5'AGT GAT CTA GGT ATT GCC ATT T 3' \\
\hline gCCC-R2 & 5'TTA CAA GAC TTC TTC GTT TGA CA 3' \\
\hline mCCC-F1 & 5'AAT GAC ATG CAG CGC CTG TAC TA 3' \\
\hline mCCC-R1 & 5’TTC AAT CAT TTC TCT GGC GGT T 3' \\
\hline mCCC-F2 & 5'TGA TGA AGT TAA ACA TGA TTC TTA C $3^{\prime}$ \\
\hline $\mathrm{mCCC}-\mathrm{R} 2$ & 5'ACA GTA TAA CAA TAT CAG CTG CTT 3' \\
\hline
\end{tabular}

Superscript II cDNA synthesis kit cat. no.: 11904-018). ATP7B (4459 bp) gene fragment was amplified using Phusion High Fidelity DNA polymerase (Finnzyme F-530S) and primers that belongs to ATP7B gene (Table 1). The fragments were cloned into pDONR vector and pAG426 yeast expression vector using gateway system (Invitrogene Gateway BP clonase enzyme mix cat. no.: 11789020, LR clonase enzyme mix cat. no.: 11791-020). Plasmids were sequenced for confirmation purposes (Macrogen Inc. European Lab).

\section{Site directed mutagenesis}

Site-directed mutagenesis was performed for p.T788I, p.V1036I and p.R1038G-fsX83 mutations using the Quickchange site directed mutagenesis kit (Stratagene). Primers used for this purpose were shown in Table 1 . The mutations were confirmed by sequencing.

\section{Yeast strains and transformation}

The plasmids (pAG426GPD) containing wild type and mutant (p.T788I, p.V1036I, p.R1038G-fsX83) ATP7B genes were transformed into $\operatorname{ccc} 2 \Delta$ yeast cells (MAT $\alpha$ his $3 \Delta 1$ leu $2 \Delta 0$ met $15 \Delta 0$ ura3 $\Delta 0 \operatorname{ccc} 2 \Delta$ ) by the standard LiAc method [11]. Transformants were selected by plating onto YNB plates without uracil.

\section{Real-time PCR}

Total RNA was isolated from yeast strains (Qiagen RNeasy Mini kit) and then cDNA was prepared (Invitrogen Superscript II cDNA synthesis kit). Real-time PCR was performed triplicate with K9F, K9R and Src-actine (F), Src-actine (R) primers (Fermentas Maxima SYBR Green/ROX qPCR master mix) (Table 1 ).

\section{Western blot}

Yeast $\Delta \mathrm{ccc} 2$ mutants containing p-ATP7B, p-T788I mutant, pV1036I mutant, p-R1038G-fsX83 mutant and sham vector (p-only) were grown to mid-log phase in YNB-Ura medium and equal number of cells ( $1 \mathrm{ml}$ of $\left.0.8 \mathrm{OD}_{600}\right)$ were harvested by centrifugation. Then, cells were resuspended in sample buffer $(0.06 \mathrm{M}$ Tris- $\mathrm{HCl} \mathrm{pH}$ $6.8,10 \%(\mathrm{v} / \mathrm{v})$ glycerol, $2 \%(\mathrm{w} / \mathrm{v})$ SDS, $5 \%(\mathrm{v} / \mathrm{v})$ 2-mercaptoethanol, $0.0025 \%(\mathrm{w} / \mathrm{v})$ bromophenol blue) and heated at $95^{\circ} \mathrm{C}$ for $5 \mathrm{~min}$. Samples were centrifuged at $14,000 \mathrm{rpm}$ for $1 \mathrm{~min}$ and $10 \mu \mathrm{L}$ of each was loaded to a $6 \%$ SDS-PAGE. Next, proteins were transferred to a PVDF membrane. Primary antibodies against ATP7B (Thermo Scientific PA-13429) and yeast phosphoglycerate kinase-1 (PGK1) (Invitrogen) were used. As secondary antibodies, goat anti-rabbit IgG conjugated to horeseradish peroxidase (Santa Cruz) and goat anti-mouse IgG conjugated to horseradish peroxidase (Sigma) were used respectively. The membranes were treated with enhanced chemiluminescence system (Milipore) and visualized using the VersaDoc Imaging System (Bio-Rad).

Yeast media, growth, and copper measurements

The assay medium consisted of YNB (Yeast Nitrogen Base) without iron and copper (Sunrise Science, San Diego, CA), which was supplemented with all necessary amino acids and bases, and $50 \mathrm{mM}$ MES buffer at $\mathrm{pH}$ 6.1. The iron-limited medium contained YNB medium with $1 \mathrm{mM}$ ferrozine (an iron specific chelator), $50 \mathrm{mM}$ ferrous ammonium sulfate, and $1 \mu \mathrm{M}$ copper sulfate. Yeast cultures grown in iron-limited medium overnight, and resuspended in fresh iron-limited medium to yield $\mathrm{OD}_{600}$ of 0.1 . Cultures were grown at $30^{\circ} \mathrm{C}$ for $24 \mathrm{~h}$ and cell growth was monitored $\mathrm{OD}_{600}$ measurements.

Copper concentrations were measured by an ICP-MS method. Supernatants were isolated after growing cells $24 \mathrm{~h}$ in iron limited YNB medium ( $50 \mu \mathrm{M}$ MES, $1 \mu \mathrm{M}$ ferrozine, $50 \mu \mathrm{M}$ ferrous ammonium sulfate, $1 \mu \mathrm{M} \mathrm{CuSO}_{4}$ completed with YNB-URA without iron and copper). Cells were centrifuged at $5000 \mathrm{rpm}$ for $5 \mathrm{~min}$ and pellets were washed and analyzed for copper contents by ICP-MS. Ultra pure water, YNB medium and iron limited medium were used as blanks and they were analyzed in triplicate by ICP-MS (Agilent 7500ce - Ar mode reading). The TMDA-70 high level fortified standard for trace elements (diluted by 10 -fold, $2 \% \mathrm{HNO}_{3}$ ) was used as the certified reference material (CRM). The samples were prepared by diluting 10 -fold in $\mathrm{HNO}_{3} .{ }^{72} \mathrm{Ge}$ isotope was used as an internal standard (50 ppb) and the ${ }^{63} \mathrm{Cu}$ copper isotope was monitored in the study using an Agilent 7500CE ICP-MS instrument.

\section{Results and discussion}

Three novel mutations in ATP7B gene (p.T788I(c.2363C $>$ T), p.V1036I(c.3106G>A) and p.R1038G-fsX83(c.3111delC)) were previously identified [10]. Clinical and laboratory findings of Wilson disease patients that have these mutations were shown in Table 2. The patients with these mutations have copper storage abnormalities in different parts of their bodies; p.T788I mutation mainly affects the liver and the nervous system, p.V1036I mutation affects 
Table 2

Clinical and laboratory findings of Wilson disease patients that have p.T788I, p.V1036I and p.R1038G-fsX83 mutations.

\begin{tabular}{|c|c|c|c|c|c|c|c|c|}
\hline \multirow[t]{2}{*}{ Patients number } & \multicolumn{4}{|l|}{ Affected organ } & \multicolumn{4}{|c|}{ Clinical and laboratory findings } \\
\hline & Mutation & Age of onset & Liver & $\begin{array}{l}\text { Brain } \\
\text { (neurological } \\
\text { abnormalities) }\end{array}$ & $\begin{array}{l}\text { Serum } \\
\text { ceruloplasmin } \\
(>20 \mathrm{mg} / \mathrm{dl})\end{array}$ & $\begin{array}{l}\text { Eye (Kayser } \\
\text { Fleisher } \\
\text { ring) }\end{array}$ & $\begin{array}{l}\text { Urinary copper } \\
\text { (40 } \mu \mathrm{g} / \text { day) }\end{array}$ & $\begin{array}{l}\text { Liver } \\
\text { biopsy } \\
(<50 \mu \mathrm{g} / \mathrm{g})\end{array}$ \\
\hline 009C1E & p.T788I & 9 & + & + & 15.0 & + & 796 & $\begin{array}{l}+ \\
(>250 \mu \mathrm{g} / \mathrm{g})\end{array}$ \\
\hline 020C1E & p.R1038G-fsX83 & 5 & + & - & 5.0 & - & 1900 & $\begin{array}{l}+ \\
(>250 \mu \mathrm{g} / \mathrm{g})\end{array}$ \\
\hline 035B1K & p.V1036I & 25 & - & + & 10.52 & + & 301 & - \\
\hline
\end{tabular}

the nervous system, and p.R1038G-fsX83 mutation causes damages to the liver [10].

To better understand the effects of these mutations on normal functions of ATP7B, we cloned human ATP7B gene onto a yeast expression vector and created the same mutations by site directed mutagenesis. Then, wild type and mutated forms of ATP7B genes were transformed into yeast cells lacking the homologous CCC2 gene for functional comparison. First, we analyzed the expression of ATP7B and its variants in yeast cells by a real time PCR approach to make sure that transformed cells express the plasmids. As seen in Fig. 1A, wild type ATP7B and its variants were all expressed successfully from plasmids and their expression levels were similar with minor changes. There was no statistically significant change between wild type ATP7B and the mutants (Mann-Whitney $U$ test, $p=0.157, p>0.05$ ). We also observed similar expressions in protein levels of the same constructs (Fig. 1B).

After observing that the plasmid constructs were expressible in yeast, we analyzed the growth dynamics of transformants under iron limiting conditions to distinguish none or hemi-functional variants of ATP7B gene. In $c c c 2 \Delta$ yeast, copper is not carried into the secretory pathway and to the Fet3p ferroxidase, which normally plays role in iron import along with the high-affinity iron transporter Ftr1p [12,13]. Without Fet3p activity, cells become inefficient in high-affinity iron uptake [14], and in result, the $\operatorname{ccc} 2 \Delta$ mutants cannot grow in iron-limited medium. Thus, expressing a functional ATP7B in ccc $2 \Delta$ yeast restores copper transport to the Fet3p, which reinstates iron uptake and the cell growth [15].

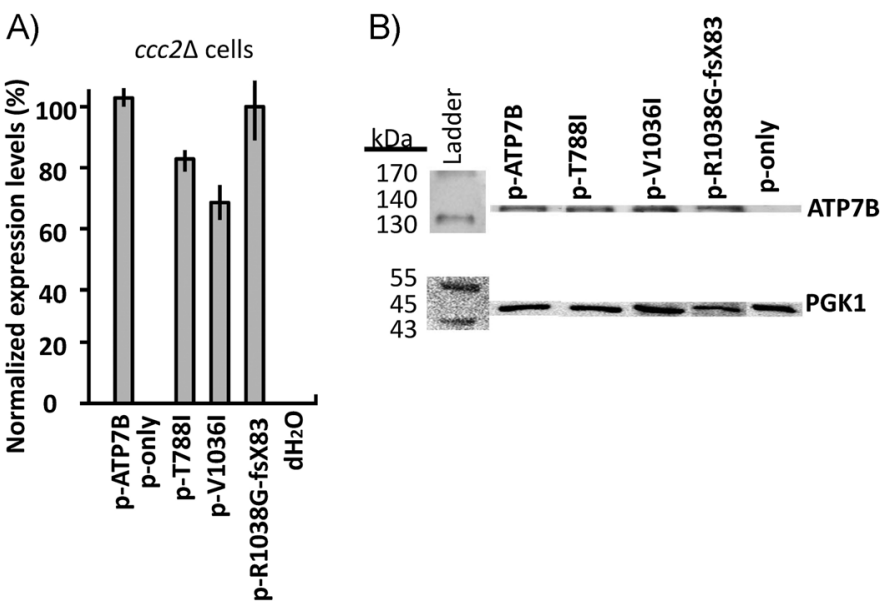

Fig. 1. Expression analyses of ATP7B constructs in yeast. (A) Real-time PCR analyses Expression of human ATP7B and its variants from plasmid pAG426 in $\operatorname{ccc} 2 \Delta$ yeast cells. Expression levels were normalized by internal actin gene. Real-time PCR was performed in triplicate and there is no statistically significant diffrences between ATP7B and its variants (Mann-Whitney $U$ test, $p=0.157$, SPSS statistics v20). Lanes that contain empty plasmid and water were used as negative control. (B) Western blot analyses of ATP7B variants in yeast cells. Yeast transformants with indicated human ATP7B constructs were analyzed by an antibody against ATP7B. Yeast phosphoglycerate kinase (PGK1) was used as the internal control. Empty vector was used as the negative control.
Our ccc $2 \Delta$ mutants carrying the empty vector ( $\mathrm{p}$-only) could not grow in iron limiting conditions (Fig. 2), but they grew well with the wild type ATP7B ( $\mathrm{p}$-ATP7B) gene. Generation time (doubling time) is a good indicator of growth rate under different conditions and it is expected that healthy cells divide faster. The wild type yeast with empty vector had a generation time of $4.2 \mathrm{~h}$, whereas $\operatorname{ccc} 2 \Delta$ mutants with human ATP7B had a generation time of $4.7 \mathrm{~h}$ under iron limiting conditions. Thus, expression of the human ATP7B gene restored the growth defect of $c c c 2 \Delta$ cells significantly (90\% complementation by the generation time). The ATP7B variants were not as effective as wild type ATP7B gene in restoring the growth defect of $\operatorname{ccc} 2 \Delta$ cells. Generation time of the cells with mutant forms of ATP7B was as follows: $5.7 \mathrm{~h}$ for $\mathrm{p}-\mathrm{T788I}, 5.4 \mathrm{~h}$ for $\mathrm{p}-\mathrm{V} 1036 \mathrm{I}$ and $5.2 \mathrm{~h}$ for p-R1038G-fsX83. Thus, mutant ATP7B variants were able to complement the yeast CCC2 function from $65 \%$ to $75 \%$.

Among these forms, p-T788I mutation rendered the function of ATP7B the most in yeast cells. This variant was isolated from patients with severe pathological findings (both liver and neurological abnormalities), and it is not surprising that it also causes the most severe phenotype in yeast cells. The V1036I mutation, which causes neurological abnormalities in patients, had a milder effect on yeast growth when compared to the p-T788I mutation. The p.R1038G-fsX83 mutation, which affects only the liver in patients [10], had the least pronounced effect on yeast growth phenotype.

Since CCC2 function is required for copper transport out of yeast cells, the $\operatorname{ccc} 2 \Delta$ mutants should accumulate copper in the cells and human ATP7B should help $c c c 2 \Delta$ cells to excrete the excess copper. To estimate the copper content of the cells, we first measured the copper levels of liquid media by ICP-MS after removal of the cells. We expected to see lower levels of copper in media for the cells that accumulate copper and cannot efflux it. As seen in Fig. 3A, after removal of cells with mutant forms of ATP7B, copper levels dropped

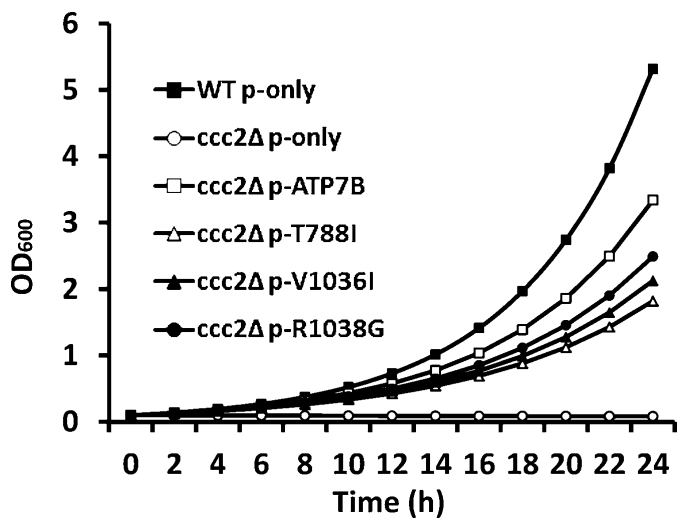

Fig. 2. Growth rate of yeast cells under iron limited conditions. The $\operatorname{ccc} 2 \Delta$ mutants carrying either sham vector ( $p$-only) or human ATP7B variants were analyzed for their ability to grow in iron limited conditions. Cell growth was followed by $\mathrm{OD}_{600}$ measurements for $24 \mathrm{~h}$. Growth rates were analyzed in triplicate and a representative assay was shown in the figure. WT cells with sham vector (WT p-only) used as positive control for cell growth. 
B) Cell pellets

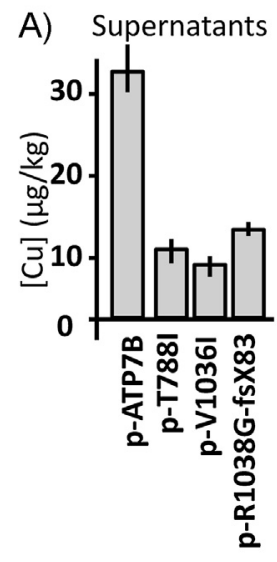

Fig. 3. Copper measurements in iron limited conditions. (A) Growth media copper levels. Cells were first grown in iron limited media and then removed by centrifugation. Copper levels of media were analyzed by ICP-MS. Bars represent mean value of 3 measurements and error bars represent the standard deviation of means. (B) Measurements of cell pellet (intracellular) copper levels. Cells were grown in iron limited media and collected by centrifugation. Intracellular copper levels were measured as indicated in methods. Bars represent mean value of 3 measurements and error bars represent the standard deviation of mean.

to less than half of that of wild type ATP7B control (Mann-Whitney $U$ test, $p=0.001, p<0.05$, SPSS statistics v20).

We also measured copper levels in cells to see that secretion deficient cells accumulate copper inside the cells. As expected, there were significant increases in copper contents of cells that harbor mutant ATP7Bs (Fig. 3B) ( $p=0.013)$. Thus, our results suggested that cells with mutant ATP7B variants are not able to secrete copper back to the media. However, we did not investigate the mechanisms of how copper is trapped in the cells in the case of mutant forms, and this issue should be further investigated.

Overall, our study identified three new mutations in ATP7B gene that leads to functional deficiencies. This study also confirms previous studies [14-16] suggesting that yeast $S$. cerevisiae is a good model for understanding functional characterization of new mutations in Wilson disease gene (ATP7B).

\section{Conflict of interest}

The authors declare that there are no conflicts of interests.

\section{Acknowledgements}

This work was supported by Dokuz Eylul University Research Foundation with project number 2010.KB.SAG.003. We thank yeast laboratory researchers of Izmir Institute of Technology for their help and convenience.

\section{References}

[1] Wilson S. Progressive lenticular degeneration: a familial nervous disease associated with cirrhosis of the liver. Brain 1912;34:295.

[2] Sterlieb I. Perspectives on Wilson's disease. Hepathology 1990;12:1234-9.

[3] Figus A, Angius A, Loudianos G, Bertini C, Dessi V, Loi A, et al. Molecular pathology and haplotype analysis of Wilson disease in Mediterranean populations. Am J Hum Genet 1995;57:1318-24.

[4] Bull PC, Thomas GR, Rommens JM, Forbes JR, Cox DW. The Wilson disease gene is a putative copper transporting P-type ATPase similar to the Menkes gene. Nat Genet 1993:5:327-37.

[5] Tanzi RE, Petrukhin K, Chernov I, Pellequer JL, Wasco W, Ross B, et al. The Wilson disease gene is a copper transporting ATPase with homology to the Menkes disease. Nat Genet 1993:5:344-50.

[6] Lutsenko S, Barnes NL, Bartee MY, Dmitriev OY. Function and regulation of human copper-transporting ATPases. Physiol Rev 2007;87:1011-46.

[7] Huster D. Wilson disease. Best Pract Res Clin Gastroenterol 2010;24:531-9.

[8] de Bie P, Muller P, Wijmenga C, Klomp LWJ. Molecular pathogenesis of Wilson and Menkes disease: correlation of mutations with molecular defects and disease phenotypes. J Med Genet 2007;44:673-88.

[9] Nevitt T. Charting the travels of copper in eukaryotes from yeast to mammals. Biomed Biochim Acta 2012;1823:1580-93.

[10] Papur OS, Akman SA, Cakmur R, Terzioglu O. Mutation analysis of ATP7B gene in Turkish Wilson disease patients: identification of five novel mutations. Eur J Med Genet 2013;56:175-9.

[11] Gietz RD, Woods RA. Transformation of yeast by the Liac/SS carrier DNA/PEG method. Methods Enzymol 2002;350:87-96.

[12] Stearman R, Yuan DS, Yamaguchi-Iwai Y, Klausner RD, Dancis A A permease-oxidase complex involved in high-affinity iron uptake in yeast. Science 1996;271:1552-7.

[13] Bonaccorsi di Patti MC, Miele R, Eugenia Schininà M, Barra D. The yeast multicopper oxidase Fet3p and the iron permease Ftr1p physically interact. Biochem Biophys Res Commun 2005;333:432-7.

[14] Yuan DS, Stearman R, Dancis A, Dunn T, Beeler T, Klausner RD. The Menkes/Wilson disease gene homologue in yeast provides copper to a ceruloplasmin-like oxidase required for iron uptake. Proc Natl Acad Sci U S A 1995;92:2632-6.

[15] Forbes JR, Cox DW. Functional characterization of missense mutations in ATP7B: Wilson disease mutation or normal variant? Am J Hum Genet 1998;63:1663-74.

[16] Hung IH, Suzuki M, Yamaguchi Y, Yuan DS, Klausner RS, Gitlin JD. Biochemical characterization of the Wilson disease protein and functional expression in the yeast Saccharomyces cerevisiae. J Biol Chem 1997;272(34):21461-6. 